\title{
How has Internet use changed between 2012 and 2015?
}

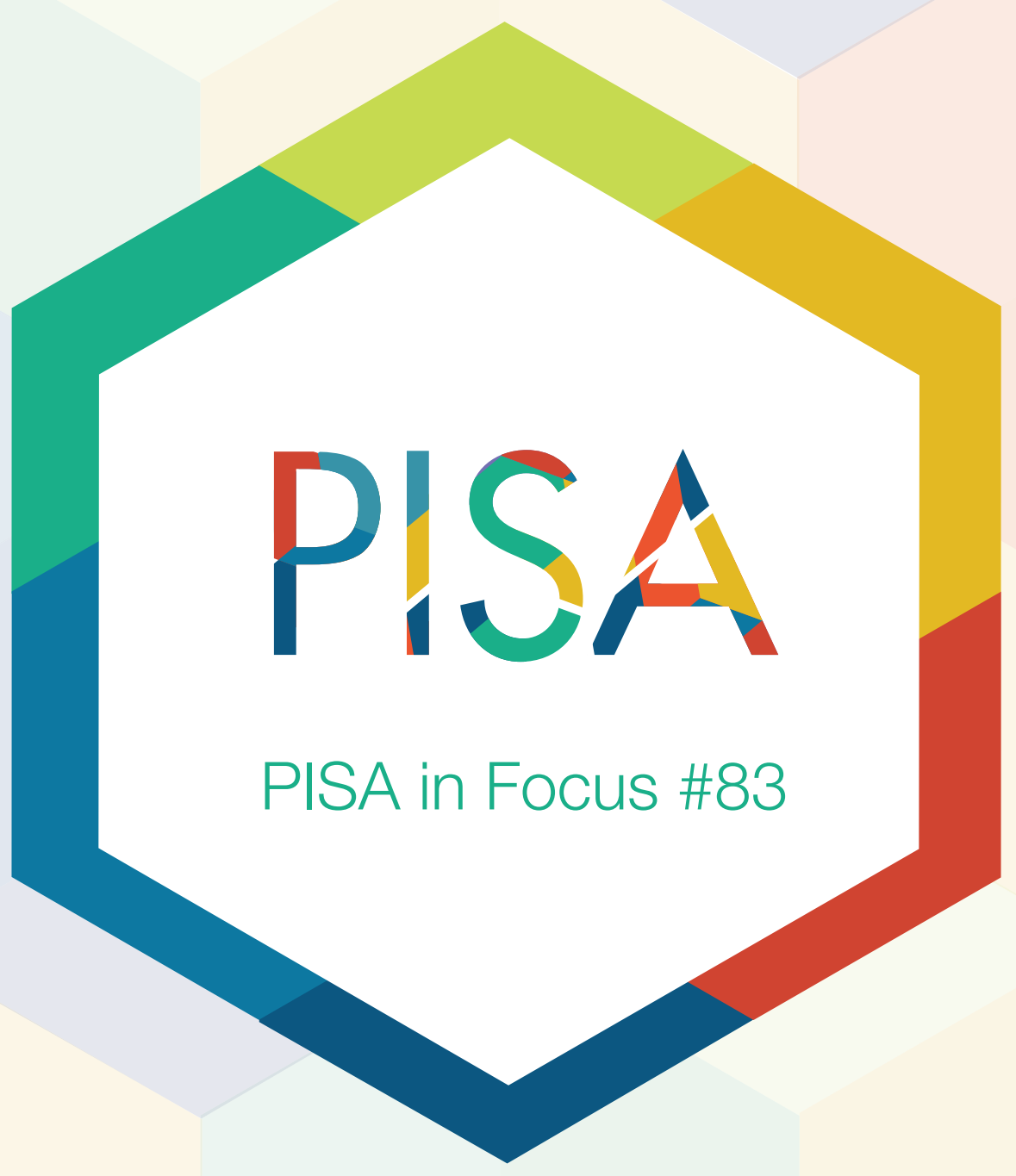




\section{How has Internet use changed between 2012 and 2015?}

- Between 2012 and 2015, the time that 15-year-olds reported spending on the Internet increased from 21 to 29 hours per week, on average across OECD countries.

- In 2015, socio-economically disadvantaged students reported spending about two hours more per week on line than advantaged students, on average across OECD countries.

- In every school system, students who reported using the Internet more frequently scored lower in science than students who reported using the Internet less frequently. However, on average across OECD countries, 15-year-olds who used the Internet moderately scored above students who never used the Internet or who used it more intensively.

In the growing world of digital technology everything is about speed: computer processors have doubled their performance every two years for decades; the future $5 \mathrm{G}$ mobile phone generation is predicted to be about 100 times faster than the current 4G and 20000 times faster than the "ancient" 3G; and, according to the International Telecommunication Union, the share of the world population using the Internet increased from $34 \%$ to $48 \%$ in just the past five years. Is this digital revolution changing adolescents' lives at the same frenzied rate? Are 15-year-olds more and more connected to the Internet? And are these changes closing the digital divide?

\section{Students around the globe are spending more time on line.}

According to the OECD report, PISA 2015 Results: Students' Well-Being, the percentage of 15-year-olds with an Internet connection at home has increased from 75\% in 2006 to 95\% in 2015, on average across OECD countries. But the increase in Internet use has been even more remarkable. PISA asked students how frequently they use the Internet, both at school and outside of school. In the three years from 2012 to 2015 , the time that 15-year-olds reported spending on the Internet increased from 21 to 29 hours per week, on average across OECD countries - an increase of more than one hour per day - with most of this increase concentrated on school days. The growth in Internet use was observed in every country and economy that distributed the ICT questionnaire in both the 2012 and 2015 cycles of PISA. Internet use grew the fastest in Chile, Costa Rica, Ireland and Italy, and slowest in Greece, Hong Kong (China), Macao (China) and Slovenia. In Costa Rica, for instance, students reported spending, on average, 36 hours per week on the Internet in 2015, compared to just 19 hours three years earlier.

Despite this overall growth, there were still wide differences across countries in the extent to which students used the Internet in 2015, especially during school days. In Japan and Korea, for instance, students reported spending fewer than 20 hours per week connected to the Internet in 2015, and as much as a third of this time was spent during weekends. By contrast, in Chile, Costa Rica, Denmark and Sweden, students reported spending more than 35 hours per week on line, a quarter of which was spent on weekends. 


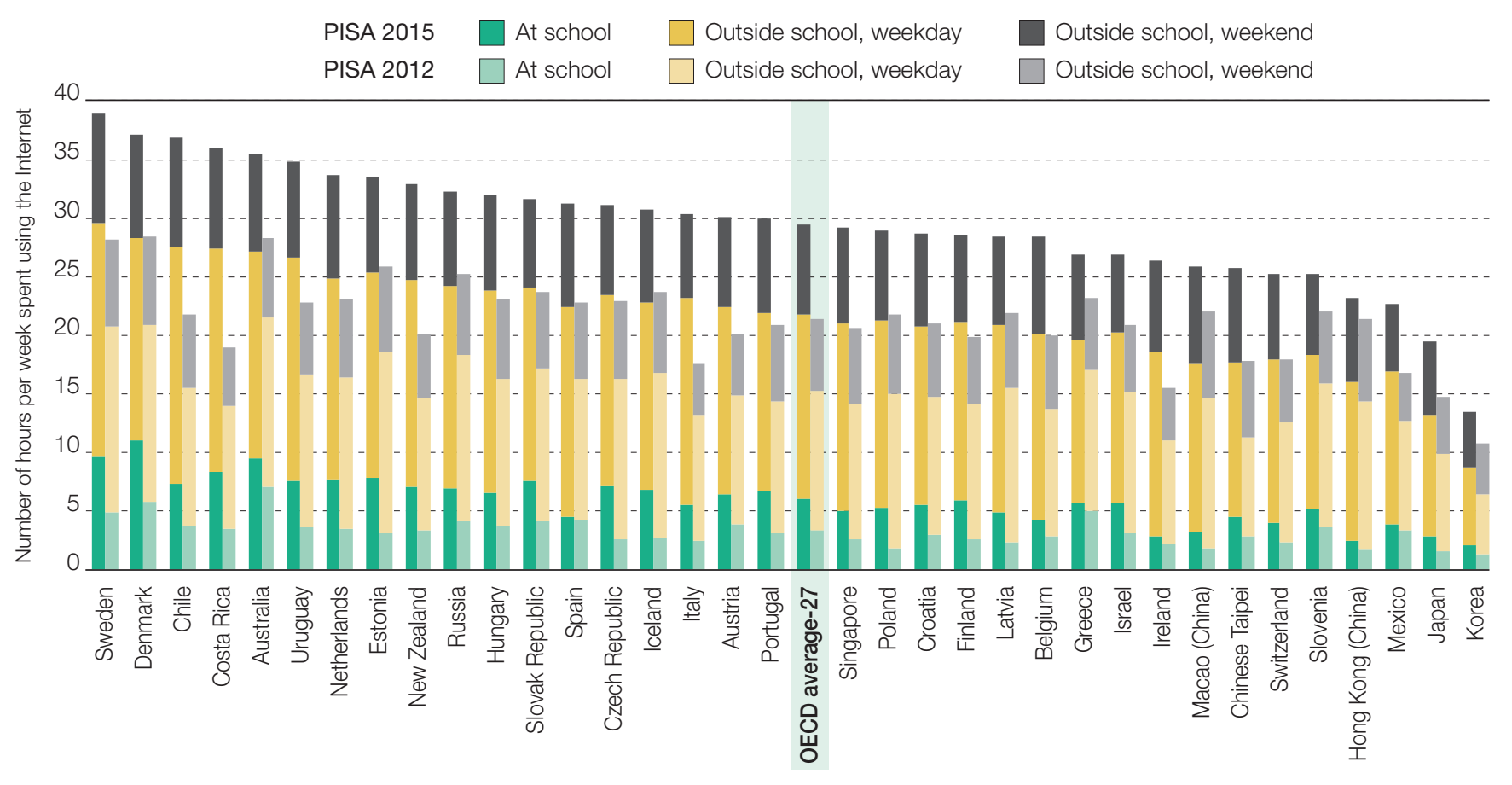

Note: To obtain the weekly average, the response categories were recoded with the middle values (e.g. "31-60 minutes per day" was recoded as "45.5 minutes per day") and then multiplied by 5 if they refer to a school day and by 2 if they refer to a weekend day.

Only countries and economies with comparable data from PISA 2012 and PISA 2015 are shown.

Source: OECD, PISA 2015 Database.

\section{There is no such thing as a digital divide in Internet use in most OECD countries.}

Even in 2012, socio-economically advantaged and disadvantaged students reported spending a similar amount of time connected to the Internet, on average across OECD countries, presumably because Internet access became virtually universal across most OECD countries in the preceding years. Interestingly, the gap may be reversing in favour of disadvantaged students, on average across OECD countries: in 2015 they reported spending about two hours more per week on line than advantaged students; and in several countries and economies, especially in Belgium and Chinese Taipei, disadvantaged students had already reported spending more time on line than their more advantaged counterparts back in 2012. While disadvantaged students used the Internet more frequently on school days, the time spent on line on weekends was the same for advantaged and disadvantaged students in 2015, on average across OECD countries.

But in Chile, Costa Rica, Latvia, Mexico, Russia and Uruguay, the traditional digital divide remains: advantaged students reported spending more time connected to the Internet than disadvantaged students - in Mexico, almost 20 hours more per week. And the digital divide persists when it comes to certain online enriching activities, such as reading news on the Internet. 


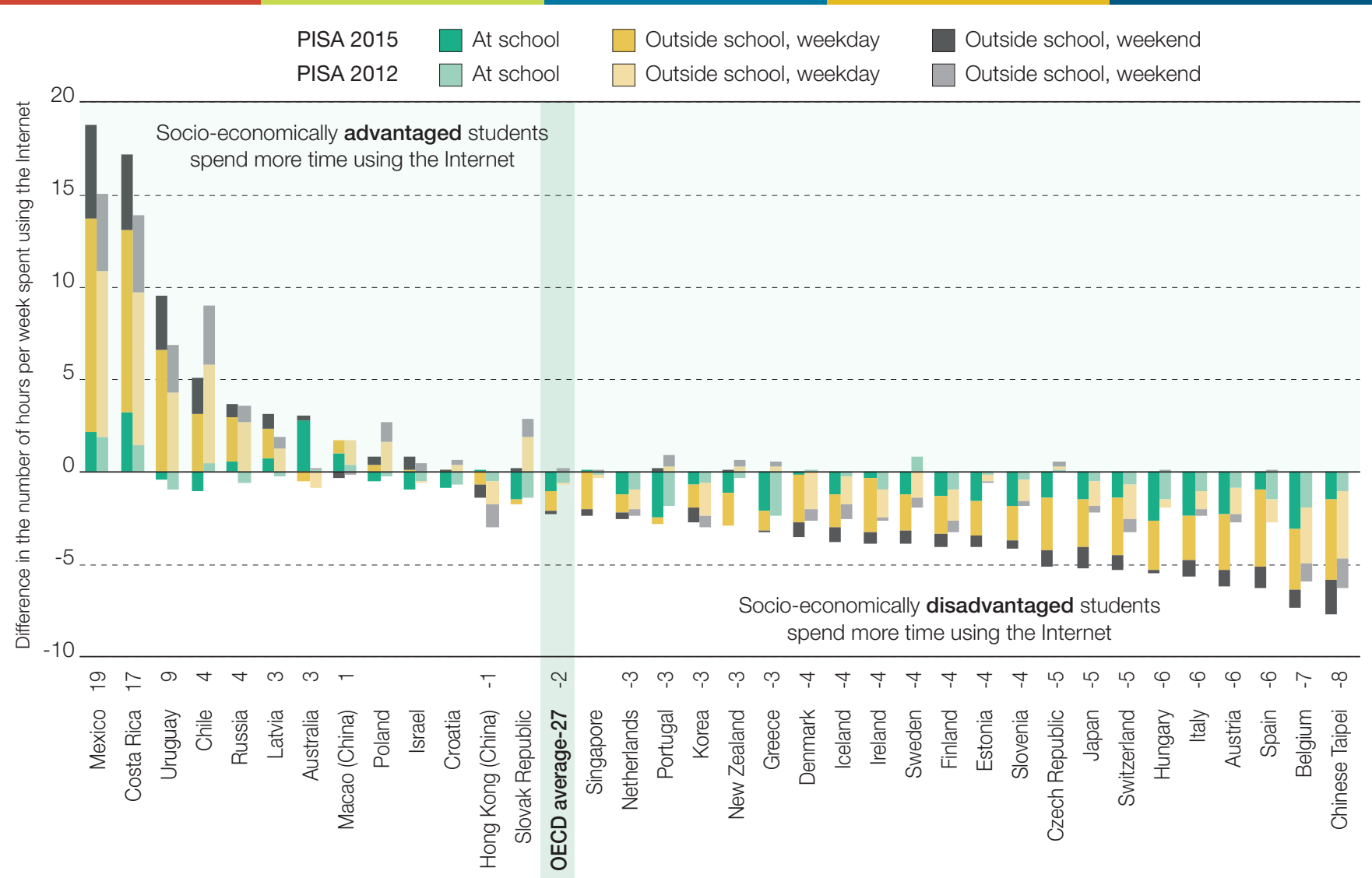

Notes: To obtain the weekly average, the response categories were recoded with the middle values (e.g. "31-60 minutes per day" was recoded as " 45.5 minutes per day") and then multiplied by 5 if they refer to a school day and by 2 if they refer to a weekend day.

Significant differences between socio-economically advantaged and disadvantaged students in the total number of hours per week spent using the Internet in 2015 are indicated next to the country/economy name.

Only countries and economies with comparable data from PISA 2012 and PISA 2015 are shown.

Source: OECD, PISA 2015 Database.

\section{However, greater connectivity may not necessarily be good news for disadvantaged students.}

As students become more and more connected, will they become more effective learners? While PISA cannot prove cause and effect, the findings are not particularly promising. In every school system, students who reported using the Internet more frequently scored lower in science than students who reported using the Internet less frequently. On average across OECD countries, students scored about two points lower in science for every hour spent weekly using the Internet at school, after accounting for their gender and socioeconomic status. Using the Internet outside of school more frequently was also negatively related to science performance, but only when students went on line on school days. In fact, students who reported spending more time using the Internet on weekends scored slightly higher in science, probably because it did not interfere with their learning time.

These results are not necessarily a call for digital abstinence, but a call for moderation. On average across OECD countries, 15-year-olds who used the Internet moderately - up to 30 minutes on a typical weekday at school, between 1 and 4 hours on a typical weekday outside of school or between 2 and 4 hours on a typical 
Number of hours per week using the Internet..

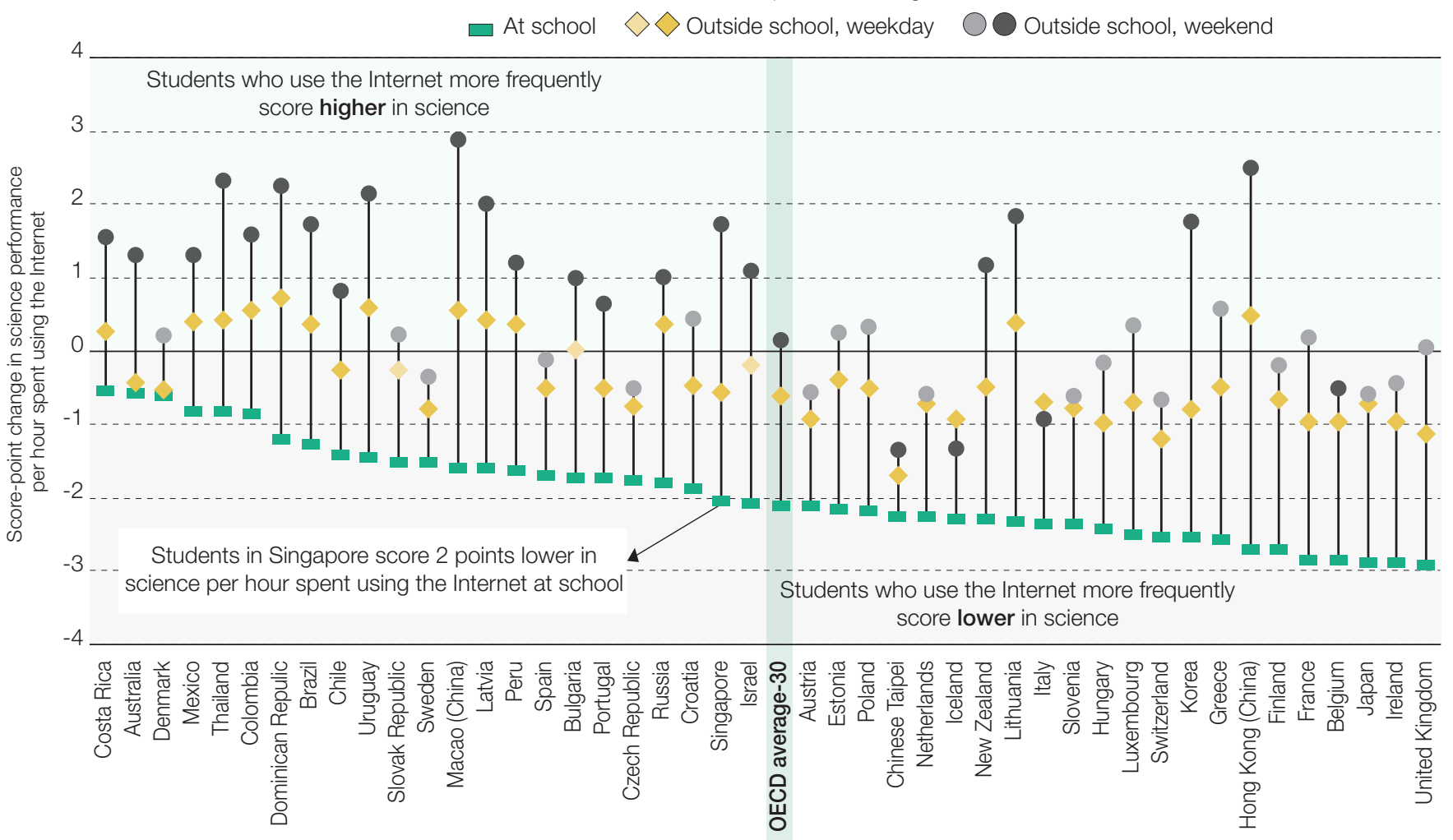

Note: To obtain the weekly average, the response categories were recoded with the middle values (e.g. "31-60 minutes per day" was recoded as " 45.5 minutes per day") and then multiplied by 5 if they refer to a school day and by 2 if they refer to a weekend day.

Only countries and economies that distributed the ICT questionnaire in PISA 2015 are shown.

Source: OECD, PISA 2015 Database.

weekend day - scored above students who never used the Internet or who used it more intensively. Using the Internet intensively - more than 6 hours per day - is also associated with less satisfaction with life, arriving late for school and lower education expectations, according to the OECD report PISA 2015 Results: Students' Well-Being. Maybe Korean and Japanese parents and students know best, and that is why 15-year-olds reported spending less time connected to the Internet compared to students in other countries, particularly on school days.

Why do digitally connected students show weaker academic performance? While PISA data cannot answer this question, previous studies suggest that personal digital devices and multitasking often distract students from core learning activities and may be detrimental to students' ability to synthesise information. Research has also found that most teachers are still ill-prepared to use digital devices effectively. Another hypothesis is that low-achieving students spend more time on the Internet because they become bored more easily while learning and doing homework. Regardless of whether using the Internet is the cause or the result of students' poor academic performance, what PISA data undeniably reveal is that high-achieving students spend less time connected to the Internet on school days than their low-achieving peers. 


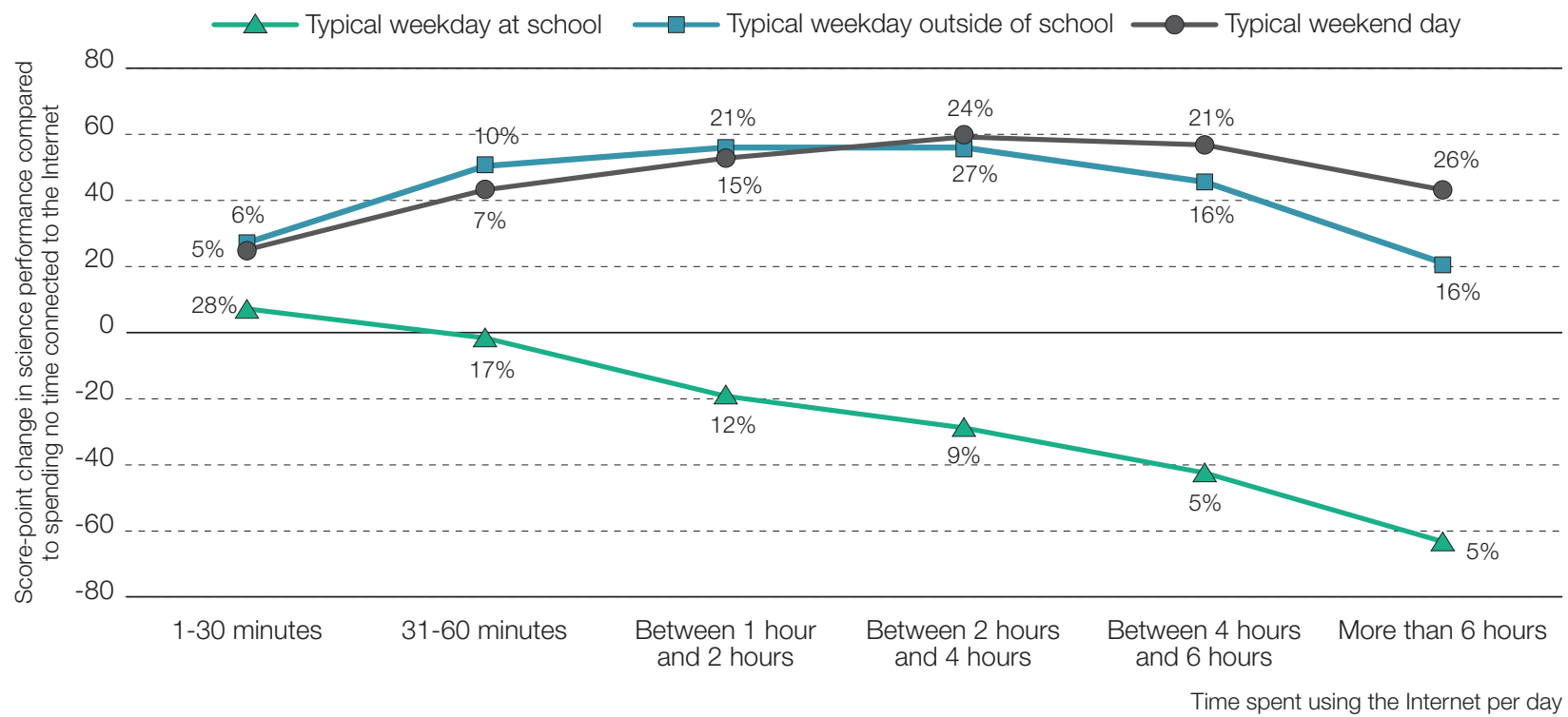

Notes: Results based on three separate linear regression models, one for each variable. Results after accounting for gender and socio-economic status. The reference category to which results are compared is "no time".

The percentage of students in each category is shown next to the marker. The remaining students answered "no time".

All coefficients are statistically significant.

Only countries and economies that distributed the ICT questionnaire in PISA 2015 are shown.

Source: OECD, PISA 2015 Database.

\section{The bottom line}

Students everywhere are spending more and more time connected to the Internet, both at and outside of school, and Internet use among disadvantaged students is increasing exponentially. While this may have been good news a decade ago, today it may be a mixed blessing: evidence suggests that digitally connected students perform worse academically, particularly when they use the Internet intensively on school days, and extreme Internet users report lower levels of well-being. There are innovative, efficient and promising ways in which digital technologies are being used in education, but until they become the norm, it may be tempting to adopt the Korean approach: spend a moderate amount of time on the Internet, and even less on school days. 



\section{For more information}

Contact: Alfonso Echazarra (Alfonso.Echazarra@oecd.org)

See: OECD (2017), PISA 2015 Results (Volume III): Students' Well-Being, OECD Publishing, Paris, http://dx.doi.org/10.1787/9789264273856-en.

Coming next month: What kinds of activities are common among teenagers who work well with others?

This paper is published under the responsibility of the Secretary-General of the OECD. The opinions expressed and the arguments employed herein do not necessarily reflect the official views of OECD member countries.

This document, as well as any data and map included herein, are without prejudice to the status of or sovereignty over any territory, to the delimitation of international frontiers and boundaries and to the name of any territory, city or area.

The statistical data for Israel are supplied by and under the responsibility of the relevant Israeli authorities. The use of such data by the OECD is without prejudice to the status of the Golan Heights, East Jerusalem and Israeli settlements in the West Bank under the terms of international law.

This work is available under the Creative Commons Attribution-NonCommercial-ShareAlike 3.0 IGO (CC BY-NC-SA 3.0 IGO). For specific information regarding the scope and terms of the licence as well as possible commercial use of this work or the use of PISA data please consult Terms and Conditions on www.oecd.org. 